\title{
The effect of uneven terrain conditions during shod vs. barefoot running
}

\author{
Jan Urbaczka ${ }^{1}$, Julia Freedman Silvernail ${ }^{2}$, Jaroslav Uchytil ${ }^{1}$, and Daniel Jandacka ${ }^{1}$ \\ ${ }^{1}$ Department of Human Movement Studies, Faculty of Education, University of Ostrava, Ostrava, Czech Republic; and ${ }^{2}$ Department of \\ Kinesiology and Nutrition Sciences, University of Nevada, Las Vegas, NV, USA
}

\section{Abstract}

Background: The majority of research on barefoot running focuses on acute changes in altering footwear without regard to the runner's experience with barefoot or minimalist footwear running. Objective: The objective of this study was to compare the effect of footwear (standard cushioned running shoes, barefoot) and running surface (flat surface, uneven terrain) on gait in experienced runners using minimalist shoes. Methods: Terrain running was simulated by three custom-made mats with randomly placed firmly attached stones. Seven experienced trail runners participated in this study. All participants were forefoot strikers. Participants underwent three-dimensional kinematic and kinetic analysis consisting of five running trials in each combination of footwear and surface. A trial was successful when the participant maintained a velocity of $3.2 \pm 0.16 \mathrm{~m} / \mathrm{s}$ without targeting a force platform. Results: Uneven terrain conditions along with barefoot conditions led to significantly decreased peak moment of ankle plantarflexion (terrain: $p=.041$, footwear: $p=.026$ ) and decreased second peak of vertical ground reaction force in comparison with other conditions (terrain: $p=.026$, footwear: $p=.004$ ). Uneven terrain conditions also significantly decreased ankle dorsiflexion at initial contact with the ground for both footwear conditions $(p=.021)$. Conclusions: We conjecture that net ankle moments could be decreased by barefoot running in terrain conditions in skilled forefoot runners. Experienced runners using minimalist shoes may incorporate trail running into their barefoot running regime without risk of higher Achilles tendon loading compared to even running.

Keywords: running, gait analysis, uneven terrain

\section{Introduction}

Running as a form of regular physical activity is becoming more popular not only on paved surfaces and running tracks in cities but also in mountain trails (Outdoor Foundation \& Montrail, 2010). This rise in popularity may be due to the higher availability of scientific research on the health benefits of running and the new excitement for running techniques (Koop \& Rutberg, 2016; McDougall, 2009). For example, the barefoot running movement, which aims at returning to a more natural form of running without modern cushioned footwear (Daoud et al., 2012). Footwear companies observed this barefoot running trend, leading to the development of minimalist shoes. The minimalist footwear theoretically combines advantages linked to running barefoot with the addition of protection against superficial injuries of the foot (Squadrone et al., 2015).

The majority of research on barefoot running focuses on acute changes in altering footwear without regard to the runner's experience with barefoot or minimalist footwear running. Consequently, it is only possible to assess adjustments to novel conditions rather than assessing specific footwear (Becker et al., 2014; Jandová et al., 2019; Sinclair et al., 2018). Despite the fact that there was a considerable number of runners using minimalist footwear, only a few studies investigated runners who were a part of naturally barefoot civilizations or runners who are experienced in minimalist footwear running (Bonacci et al., 2013; Davis, 2014; Lieberman et al., 2010; Squadrone \& Gallozzi, 2009).

Initial research has established differences in the kinetics and kinematics of barefoot and shod running (Hall et al., 2013; McCallion et al., 2014). Habitually shod runners, wearing cushioned shoes experience higher passive peak and a higher active peak of ground reaction force than runners who habitually run barefoot or in minimalist shoes (Hall et al., 2013). Furthermore, evidence exists that barefoot running is associated with increased knee flexion and ankle plantarflexion angle at initial contact with the ground compared to a neutral shoe (Hall et al., 2013; Squadrone \& Gallozzi, 2009). Spaich et al. (2009) suggested that these kinematic changes during barefoot running may result from altered proprioception. Additionally, enhanced proprioception may lead to a stiffer foot thereby altering force transfer. However, there is a lack of scientific evidence for these implications during a trail running setting (McGinnis, 2013).

Little is known about mechanical advantages or disadvantages of barefoot running compared to standard

$\triangle$ Corresponding author: Jan Urbaczka, e-mail jan.urbaczka@osu.cz, ORCID ${ }^{\circledR}$ record https://orcid.org/0000-0003-1669-189X

Article history: Received August 22 2020, Accepted January 5 2021, Published March 252021

Copyright: (c) 2021 The Author(s). Published by Palacký University Olomouc. This is an open access article distributed under the terms of the Creative Commons Attribution License (https://creativecommons.org/licenses/by/4.0/), which permits unrestricted use, distribution, and reproduction in any medium, provided the original author and source are credited. This license does not cover any third-party material that may appear with permission in the article. 
cushioned shoes during trail running (Fuller et al., 2015; Vercruyssen et al., 2016). To date, a few studies compared running on uneven and flat terrain, but only in rearfoot strike runners (Apps et al., 2017; Müller et al., 2010; Voloshina $\&$ Ferris, 2015). Authors consistently reported that uneven surface triggered increased step frequency, reduced step length (Sterzing et al., 2014; Voloshina \& Ferris, 2015), increased knee and hip flexion and reduced ankle angle at initial contact (Sterzing et al., 2014). However, all of these studies were carried on a motorised treadmill, which could affect both kinematic and kinetic parameters (Chambon et al., 2015; Fellin et al., 2010; Nigg et al., 1995).

Therefore, the aim of this study was to compare lower extremity kinematics and kinetics of experienced runners in different types of footwear (standard cushioned running shoes / barefoot) and running surface (flat surface running / uneven terrain running). We hypothesized that, due to improved proprioception during barefoot conditions, there would be a significant decrease in ankle dorsiflexion angle and a significant increase in knee flexion and hip flexion angles in the same velocity (Emborg et al., 2009; Spaich et al., 2009). In addition, due to altered force transfer from foot, there would be a greater plantarflexion moment during uneven terrain barefoot running (Enoka, 2008). Lastly, due to the influence of lowered active peak of ground reaction force (GRF) during barefoot conditions, there would be a significant decrease in the knee and hip extension moments, especially in uneven terrain (Hall et al., 2013; Lieberman et al., 2010).

\section{Methods}

\section{Participants}

An a priori sample size estimation was made on the results of a published study (Squadrone \& Gallozzi, 2009). The experimental sample was based on a key variable (ankle angle $-15 \mathrm{~ms}$ before touchdown) in different footwear conditions (neutral protective running shoes vs. barefoot). Across results, 6 participants were needed to detect significant group effects (effect size $=0.7, p<.05$, power $>.90$ ) . Accordingly, seven long-distance trail runners (6 males, 1 female) were analysed for this study. The ranges of the age, height, mass and body mass index of the subjects were 17 to 44 years $(M \pm S D: 23.29 \pm 9.45$ years $), 1.66$ to 1.89 $\mathrm{m}(1.81 \pm 0.08 \mathrm{~m}), 60$ to $80 \mathrm{~kg}(69.49 \pm 6.47 \mathrm{~kg})$, and 18.7 to $22.6 \mathrm{~kg} / \mathrm{m}^{2}\left(21.31 \pm 1.70 \mathrm{~kg} / \mathrm{m}^{2}\right)$, respectively. All participants had at least 1 year of running experience in minimalist shoes, ran at least 40 kilometres $(\mathrm{km})$ a week (in minimalist shoes or barefoot), and had no history of lower limb surgery or injury within the last year. All participants were informed of the experimental procedures and each provided written consent to participate. Ethical approval for the initiation of the study was granted by the institutional review board of the principal author.

\section{Experimental set-up}

Kinetic data were obtained from two force platforms (Kistler 9286 AA, Kistler Group, Winterthur, Switzerland) sampling at $1200 \mathrm{~Hz}$ and built into a 17-m-long runway.
Three-dimensional kinematic data of the pelvis and right leg were obtained by an optoelectronic stereophotogrammetry system consisting of eight cameras sampling at 240 $\mathrm{Hz}$ (Oqus 100, Qualisys, Gothenburg, Sweden). Kinematic and kinetic data were collected through the same software program to time synchronize the collected data. Running velocity was recorded using two photoelectric cells (P-2RB/1, EGMedical s.r.o., Brno, Czech Republic) placed along a laboratory runway.

Terrain conditions were simulated by using three custom-made mats consisting of firmly placed stones that were random in placement. Overall, the length of these mats was approximately $7 \mathrm{~m}$. One of the mats was made to fit the exact dimensions of a force plate (Figure 1).

\section{Protocol}

After a short laboratory familiarization period that included baseline somatic measurements, each participant chose the proper size of laboratory standard cushioned shoes (Mizuno Crusader 3, Mizuno Corp., Osaka, Japan) for the experiment. All participants underwent qualitative footstrike screening when they did not meet the forefoot strike criteria they were excluded (Lieberman et al., 2010). Next, participants went through a 15-minute general individual warm-up in both footwear conditions (standard cushioned shoes and barefoot). Following the warm-up, retro-reflective markers were placed by the same investigator on the right lower limb (foot, calf, and thigh) and pelvis (Figure 2). The calibration markers were placed

Figure 1 Mats simulating terrain conditions (red dashed border highlights the space where is the force platform)

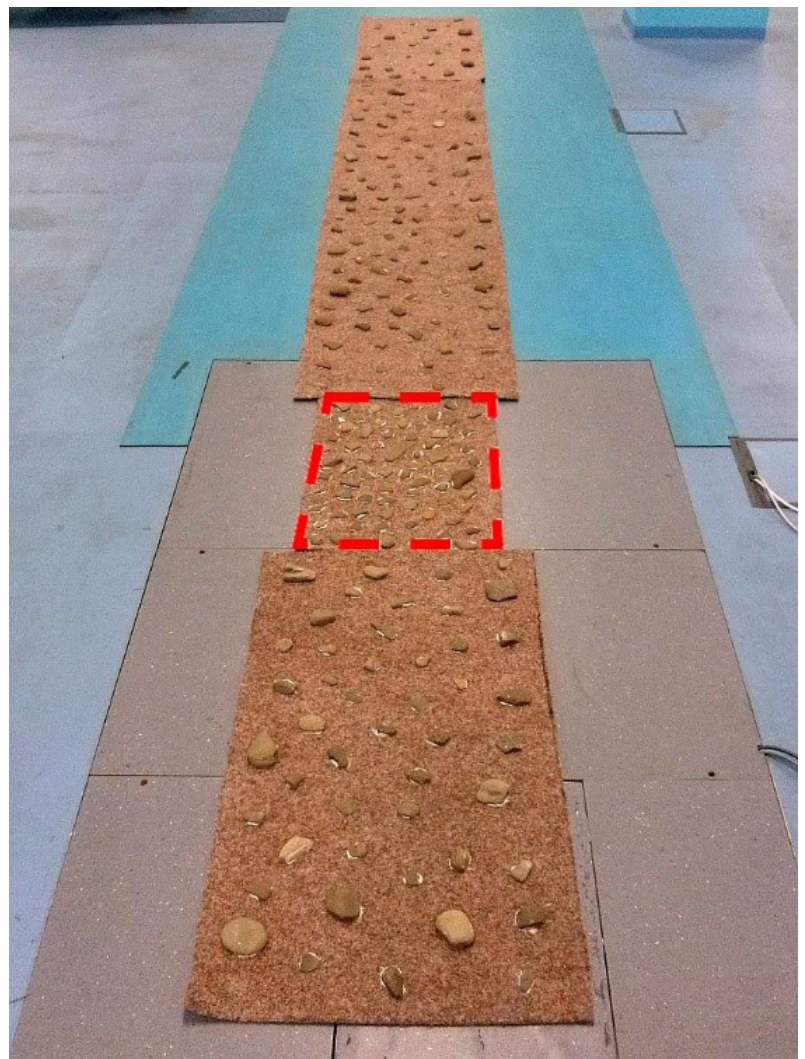




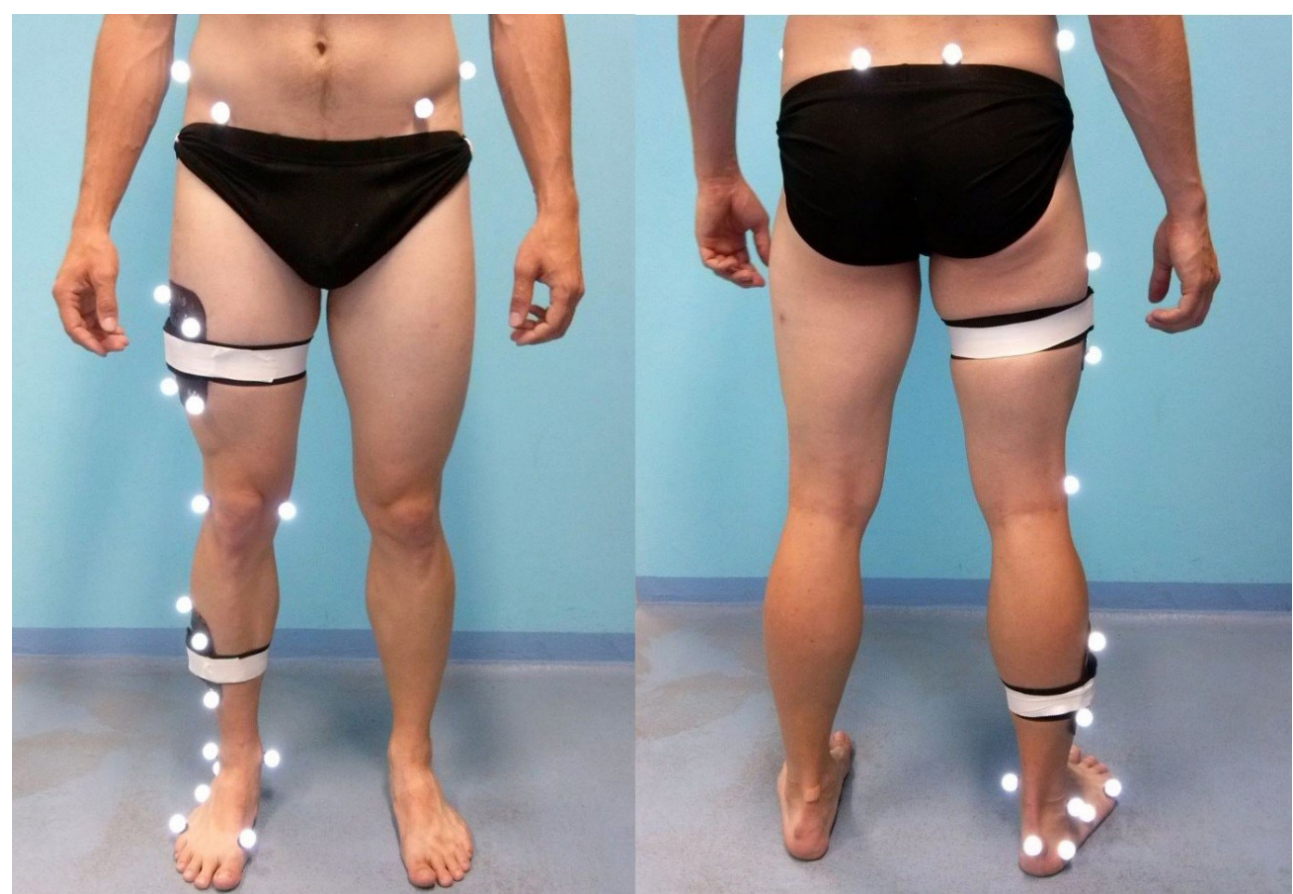

unilaterally (right leg) on the lateral and medial malleolus, the medial and lateral femoral epicondyles, the greater trochanter of the femur, and on the feet over the first and fifth metatarsal heads. Tracking markers were positioned on the iliac spines, the anterior and posterior superior iliac crests and three on the posterior aspect of the foot. Additionally, two hard light-weight plates each with four tracking markers were placed on the right thigh and shank. After marker placement, participants were given a short 3-minute period to become comfortable running with attached markers. Before a particular measurement process, participants had a 5-minute interval to get accustomed to each of the four conditions combining the certain type of shoes (standard cushioned and barefoot) and surface (uneven terrain and flat surface). After each familiarization period, data collection began. A trial was successful when the participant ran at a velocity of $3.20 \pm 0.16 \mathrm{~m} / \mathrm{s}$ while looking straight ahead. Each condition consisted of five successful trials. The order of the conditions was randomized to prevent an order effect.

\section{Data analysis}

Trajectory and force plate data were processed using Qualisys Track Manager (Version 2020.1; Qualisys, Göteborg, Sweden) and Visual 3D software (Version 6.03.6; C-motion, Rockville, MD, USA). The kinematic and kinetic data were filtered using a low-pass Butterworth filter with a $12 \mathrm{~Hz}$ and $30 \mathrm{~Hz}$ cut-off frequency, respectively. Angles in the lower limb joints were determined throughout the entire stance phase. All force data were presented as an absolute value. Three-dimensional lower extremity joint angles at the instant of initial contact and the range of joint motion were determined. Initial contact was based on the threshold vertical force value of $15 \mathrm{~N}$. In addition, maximal values of lower extremity joint moments during the stance phase of running, along with the second peak of vertical GRF, were determined in the sagittal plane (Rice et al., 2016).

\section{Statistical analysis}

Means and standard deviations from twenty stance phases per participant were calculated for each dependent variable in each condition. Statistical analysis was performed using IBM SPSS Statistics (Version 24; IBM, Armonk, NY, USA) with primary outcomes of the maximum, minimum and the value of initial contact for kinematic data. The primary outcomes from kinetic data were the second peak of vertical GRF and net moments of lower extremity joints. After the test of variables normality (ShapiroWilk test) differences between each condition (standard cushioned shoes, flat surface; standard cushioned shoes, uneven terrain; barefoot, flat surface; barefoot, uneven terrain) were tested by repeated measures two-way analysis of variance. The level of significance was stated at $p<.05$. In addition, effect sizes (ES) were calculated to aid in the interpretation of any trends. Values $<0.2,0.2-0.6,0.6-$ $1.2,1.2-2.0$, and $2.0-4.0$ were considered to be trivial, small, moderate, large, and very large effect sizes, respectively (Cohen, 1988).

\section{Results}

There was no significant effect of interaction between two analysed factors (footwear and terrain) for any of the dependent variables.

\section{Running kinetics}

The results from kinetic analysis of running in a different type of shoe (standard cushioned shoes, barefoot) regarding 
the running surface (flat surface, uneven terrain) are shown in Table 1 and Figures 3 and 4. Both terrain and footwear conditions had a significant effect on the ankle plantarflexion moment ( $p=.041$ and $p=.026$, respectively), likewise, the second peak of GRF $(p=.026$ and $p=.004$, respectively). Thus, the peak ankle plantarflexion moment and the second peak of GRF were greater during flat surface shod running. The peak knee flexion moment, peak hip flexion moment and stance time showed no significant effect in both terrain and footwear conditions.

\section{Running kinematics}

The results from the kinematic analysis showed a significant effect of terrain only for ankle dorsiflexion angle during initial contact. The ankle dorsiflexion angle was greater in a flat surface ( $p=.021$, flat surface: $25.10 \pm 6.78^{\circ}$ [barefoot] vs. $30.53 \pm 5.93^{\circ}$ [shod], uneven terrain: $26.84 \pm 6.61^{\circ}$ [barefoot] vs. $30.94 \pm 4.91^{\circ}$ [shod]). All results from threedimensional kinematics in the frontal and sagittal planes are displayed in Table 1 and Figure 5.

\section{Discussion}

The present study sought to determine the effect of uneven terrain during shod vs. barefoot running in skilled runners using minimalist shoes. In our first hypothesis, we expected a significant decrease in ankle dorsiflexion angle and a significant increase in knee flexion and hip flexion angles in barefoot conditions during running at the same velocity due to better proprioception (Emborg et al., 2009; Spaich et al., 2009). Findings from the kinematic analysis of barefoot running in both terrains partly support this hypothesis. There was a significant decrease in ankle dorsiflexion angle at initial contact $(p=.021$; Table 1 , Figure 5$)$ and at the peak value of ankle dorsiflexion angle $(p=.004$, flat surface: $92.7 \pm 1.9^{\circ}$ [barefoot] vs. $87.7 \pm 5.1^{\circ}$ [shod], uneven terrain: $94.4 \pm 2.3^{\circ}$ [barefoot] vs. $87.4 \pm 4.0^{\circ}$ [shod]) during barefoot conditions. Adopting a flatter foot placement at initial contact (which is frequently associated with a forefoot strike [FFS] or midfoot strike [MFS] pattern) could elicit lower impact forces during barefoot running (Thompson et

Table 1 Kinetics and kinematics of running barefoot and in cushioned shoes in different types of surface. Displayed are group means $\pm S D$ s and $p s$ for conditions and interaction.

\begin{tabular}{|c|c|c|c|c|c|c|c|}
\hline \multirow[b]{2}{*}{ Variable } & \multicolumn{2}{|c|}{ Barefoot } & \multicolumn{2}{|c|}{ Shod } & \multicolumn{3}{|c|}{$p$} \\
\hline & Flat surface & Uneven terrain & Flat surface & Uneven terrain & Terrain & Footwear & $\begin{array}{c}\text { Footwear } \\
\times \text { Terrain }\end{array}$ \\
\hline \multicolumn{8}{|l|}{ Kinetics } \\
\hline Peak ankle plantarflexion moment ( $\mathrm{Nm} / \mathrm{kg})$ & $-3.14 \pm 0.29$ & $-2.71 \pm 0.31$ & $-3.26 \pm 0.37$ & $-3.10 \pm 0.23$ & .041 & .026 & .077 \\
\hline Peak knee flexion moment $(\mathrm{Nm} / \mathrm{kg})$ & $-1.02 \pm 0.21$ & $-1.33 \pm 0.23$ & $-1.16 \pm 0.38$ & $-1.26 \pm 0.30$ & .055 & .756 & .329 \\
\hline Peak hip flexion moment (Nm/kg) & $-3.21 \pm 0.52$ & $-3.82 \pm 0.85$ & $-3.56 \pm 0.81$ & $-4.26 \pm 1.77$ & .149 & .36 & .936 \\
\hline Second peak of relative GRF (bodyweights) & $2.59 \pm 0.37$ & $2.34 \pm 0.30$ & $2.65 \pm 0.36$ & $2.55 \pm 0.36$ & .026 & .004 & .114 \\
\hline Time during stance phase $(\mathrm{s})$ & $0.225 \pm 0.012$ & $0.235 \pm 0.012$ & $0.231 \pm 0.009$ & $0.231 \pm 0.015$ & .106 & .596 & .067 \\
\hline \multicolumn{8}{|l|}{ Kinematics (degrees) } \\
\hline Ankle dorsiflexion, IC & $25.10 \pm 6.78$ & $26.84 \pm 6.61$ & $30.53 \pm 5.93$ & $30.94 \pm 4.91$ & .021 & .151 & .340 \\
\hline Ankle dorsiflexion, ROM & $27.79 \pm 5.27$ & $31.12 \pm 5.34$ & $28.43 \pm 4.15$ & $28.24 \pm 3.44$ & .099 & .493 & .068 \\
\hline Knee extension, IC & $-17.64 \pm 5.51$ & $-19.76 \pm 6.61$ & $-18.91 \pm 7.81$ & $-19.31 \pm 6.58$ & .370 & .756 & .385 \\
\hline Knee extension, ROM & $29.74 \pm 3.76$ & $27.39 \pm 5.87$ & $30.51 \pm 4.03$ & $29.70 \pm 4.77$ & .424 & .298 & .624 \\
\hline Hip flexion, IC & $39.73 \pm 3.79$ & $42.28 \pm 5.11$ & $40.36 \pm 4.87$ & $40.35 \pm 4.79$ & .146 & .423 & .064 \\
\hline Hip flexion, ROM & $33.67 \pm 3.11$ & $33.92 \pm 6.63$ & $33.53 \pm 4.02$ & $33.36 \pm 4.19$ & .973 & .757 & .825 \\
\hline
\end{tabular}

Note. $\mathrm{GRF}=$ ground reaction force; $\mathrm{IC}=$ initial contact; $\mathrm{ROM}=$ range of motion .

Figure 3 Ankle plantarflexion moment plotted as a function of stance phase time in percentage value

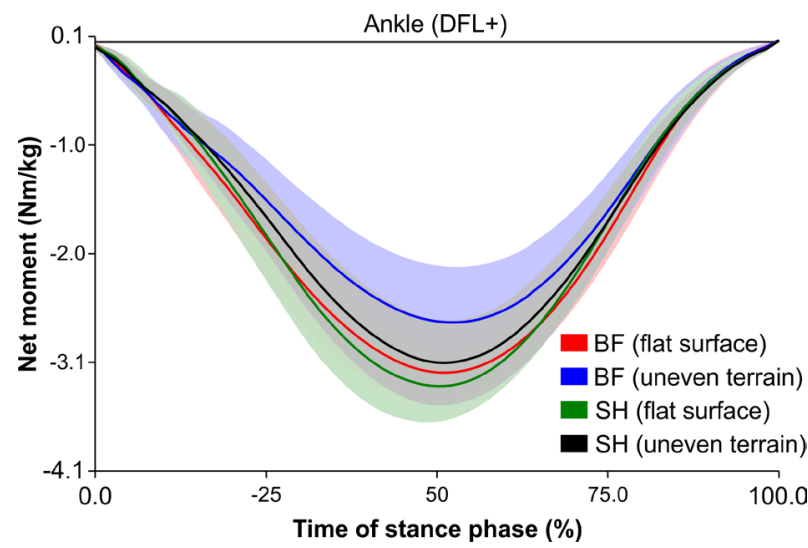

Note. $\mathrm{DFL}=$ dorsiflexion; $\mathrm{BF}=$ barefoot; $\mathrm{SH}=$ shod .
Figure 4 Ground reaction force plotted as a function of stance phase time in percentage value

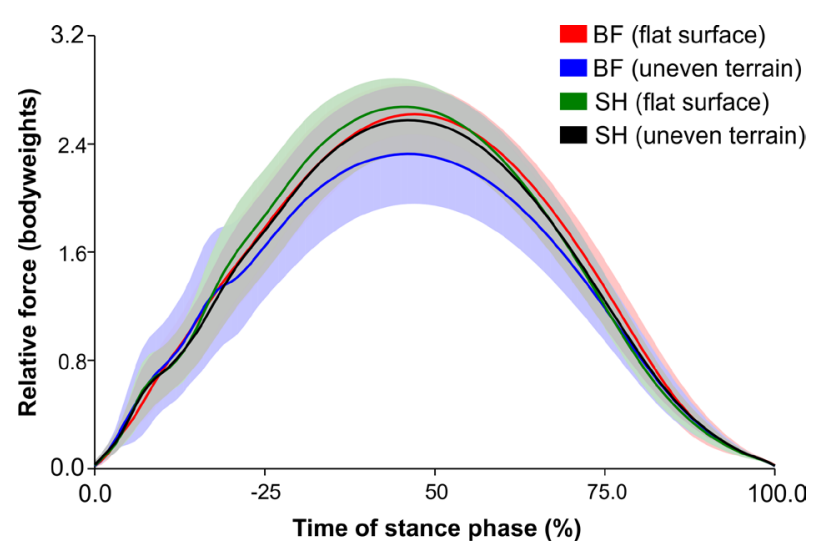

Note. $\mathrm{BF}=$ barefoot; $\mathrm{SH}=$ shod. 
Figure 5 Ankle dorsiflexion, knee extension, hip flexion angles (a) and ankle inversion, knee adduction, hip adduction angles (b) plotted as a function of stance phase time in percentage value

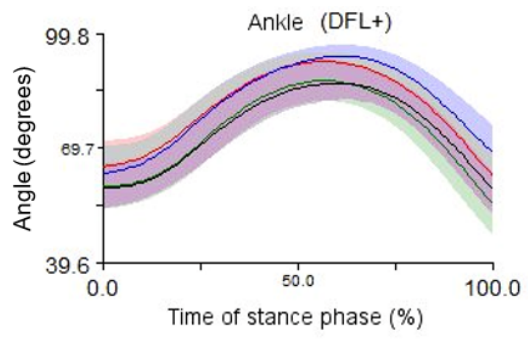

a)

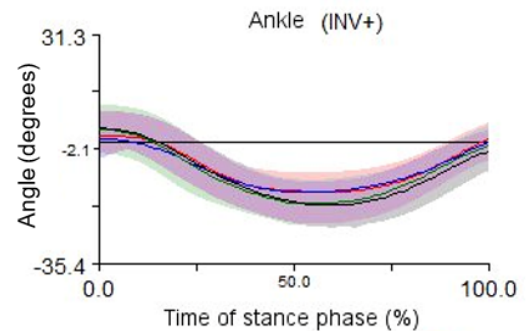

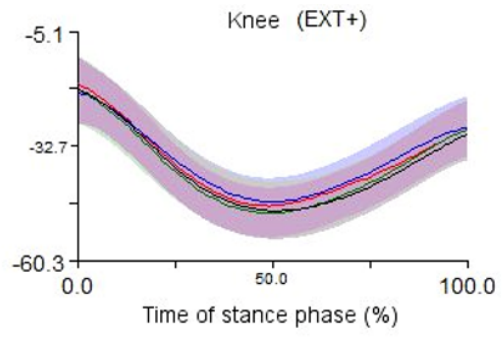

BF (flat surface) $\mathrm{SH}$ (flat surface)

- $\mathrm{BF}$ (uneven terrain) $\mathrm{SH}$ (uneven terrain)

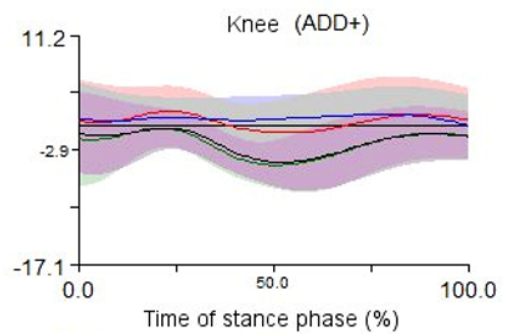

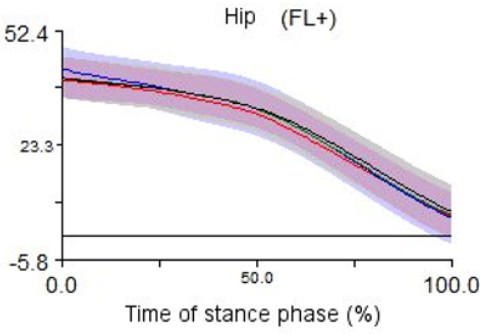

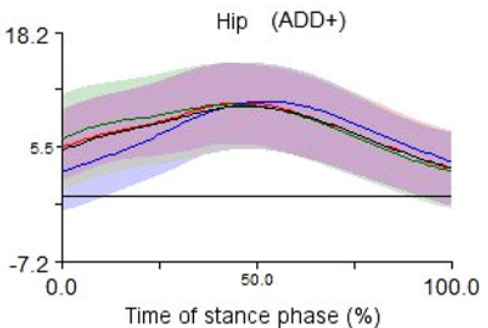

b)

Note. $\mathrm{DFL}=$ dorsiflexion; $\mathrm{EXT}=$ extension; $\mathrm{FL}=$ flexion; $\mathrm{INV}=$ inversion; $\mathrm{ADD}=$ adduction; $\mathrm{BF}=$ barefoot; $\mathrm{SH}=$ shod.

al., 2015). This probably occurs due to a protective response resulting from a plantar sensation in order to reduce shock under the heel (De Wit et al., 2000; Robbins \& Gouw, 1990). Additionally, there were no significant differences in hip and knee angles, likewise in initial contact values of hip and knee angles across all conditions. This occurred probably due to the high level of participants experience in minimalist shoes running. Therefore, they were able to maintain the same ranges of movement in other lower extremity segments, except from ankle adapting to acute changes in ground conditions (Tam et al., 2017).

We also hypothesized that there would be a higher plantarflexion moment during uneven terrain barefoot running than in other running conditions. This hypothesis was based on the presence of the withdrawal reflex, which is known to alter muscle activation due to changes in proprioception (Enoka, 2008; McGinnis, 2013). We expected that enhanced proprioception during barefoot conditions would lead to increased activation of flexor muscles and a greater transfer of force towards distal segments of the lower extremity. However, our data do not support this hypothesis. We observed a decrease in the peak ankle plantarflexion moment during barefoot uneven terrain running compared to shod uneven terrain running ( $p=.041$, Table 1$)$. Barefoot running is commonly associated with greater ankle moments (Bonacci et al., 2013). Increased ankle moments apply greater stress to the Achilles tendon, which could increase injury risk (Gruber et al., 2011). The results of our study indicate that, due to lower ankle moments, the Achilles tendon stress may be lower during terrain conditions. These findings could be important for skilled FFS runners who are aware of barefoot running benefits, but probably they are not running barefoot, because of possible overloading of their Achilles tendons. Although these results are inconsistent with previous studies of flat surface running (Bonacci et al., 2013; Squadrone \& Gallozzi, 2009), these studies did not assess uneven terrain running, which we expected to exaggerate the withdrawal reflex. We postulate that this unanticipated finding may relate to the experience of the runners in the current study. Our runners had trained in only minimalist shoes for at least one year before participating in the study. Novice barefoot or minimalist shoes runners may be more sensitive to enhanced proprioception, thus may exhibit changes in gait resulting from the uneven terrain. Future studies comparing skilled and novice runners using minimalist shoes in various terrains would provide clarity in acute and long-term gait alterations and are, therefore, recommended.

Lastly, we hypothesized that we would observe a decrease in the knee and hip extension moments due to a lower active peak of GRF during barefoot conditions. We expected that the uneven terrain would have the lowest active peak GRF. Supporting the previous research, there was a significant decrease in the active peak of vertical GRF values during all barefoot conditions (Lieberman et al., 2010). The lowered active peak of vertical GRF is also associated with FFS or MFS pattern, which may relate to the decreased injury rate of competitive runners (Daoud et al., 2012). Furthermore, Lieberman (Lieberman et al., 2010) suggests that FFS and MFS runners experience lower impact transients of vertical GRF than rearfoot strike runners. Our group of participants comprised of FFS runners, which is in an agreement with this idea.

Contrary to expectations, we found no significant differences in hip and knee extension moments during both barefoot conditions compared to shod conditions. Nevertheless, there were higher hip moments during both barefoot conditions in comparison to shod conditions (flat 
surface: $\mathrm{ES}=0.51$, uneven terrain: $\mathrm{ES}=0.32$ ). Despite higher hip moments in both footwear conditions, there were lower knee flexion moments during barefoot running in terrain conditions $(\mathrm{ES}=-0.26)$ and higher knee flexion moments during barefoot flat surface running ( $E S=0.46$ ). Differences in knee and hip joint moments during barefoot and shod conditions may be related to differences in stride length. Derrick et al. (1998) suggested that the impact characteristics will be greater in barefoot running if the stride length and footfall pattern of particular runner are maintained the same as in shoes. However, future studies with a bilateral analysis of running incorporating stride length measures are required to confirm this.

Finally, several limitations to this study need to be acknowledged. First, conclusions of this study were formed based upon the unilateral data we collected. We also do not have measurements of EMG activity thus we are not able to confirm hypotheses based on anticipated changes in muscle activity. Therefore, the current study was unable to analyse bilateral gait variables such as stride length and stride width. Secondly, the sample size was relatively small because of the specific inclusion criteria for the participants. In order to reduce the inter-subject variation on mean changes, we increased the number of processed trials per each participant. Lastly, the uneven terrain, which we used during the testing procedure represents only a small portion of common running terrains. Furthermore, trail running is usually associated with a continual change of incline, which was not considered in our study. Thus, caution should be applied when generalizing these results.

\section{Conclusions}

In conclusion, we observed skilled runners using minimalist shoes exhibiting a couple of kinematic changes across four running conditions. There was a significant decrease in the peak ankle plantarflexion moment and a decrease in the active GRF peak during barefoot running in terrain conditions. We conjecture that experienced runners using minimalist shoes may incorporate trail running into their barefoot running regime without risk of higher Achilles tendon loading compared to even running.

\section{Acknowledgments}

This work was supported by the University of Ostrava [grant number SGS14-6187-1610] and the European Union and the Ministry of Education, Youth and Sports of the Czech Republic [grant number CZ.02.1.01/0.0/0.0/16_019/0000 798 Program 4 HAIE]

\section{Conflict of interest}

The authors report no conflict of interest.

\section{References}

Apps, C., Sterzing, T., O’Brien, T., Ding, R., \& Lake, M. (2017). Biomechanical locomotion adaptations on uneven surfaces can be simulated with a randomly deforming shoe midsole. Footwear Science, 9(2), 65-77. https://doi.org/10.1080 $\lcm{19424280.2017 .1293175}$
Becker, J., Pisciotta, E., James, S., Osternig, L. R., \& Chou, L.-S. (2014). Center of pressure trajectory differences between shod and barefoot running. Gait \& Posture, 40(4), 504-509. https://doi.org/10.1016/i.gaitpost.2014.06.007

Bonacci, J., Saunders, P. U., Hicks, A., Rantalainen, T., Vicenzino, B. G. T., \& Spratford, W. (2013). Running in a minimalist and lightweight shoe is not the same as running barefoot: A biomechanical study. British Journal of Sports Medicine, 47(6), 387-392. https://doi.org/10.1136/bjsports-2012-091837

Chambon, N., Delattre, N., Guéguen, N., Berton, E., \& Rao, G. (2015). Shoe drop has opposite influence on running pattern when running overground or on a treadmill. European Journal of Applied Physiology, 115(5), 911-918. https://doi. org/10.1007/s00421-014-3072-x

Cohen, J. (1988). Statistical power analysis for the behavioral sciences (2nd ed.). Routledge. https://doi.org/10.4324/9780203771587

Daoud, A. I., Geissler, G. J., Wang, F., Saretsky, J., Daoud, Y. A., \& Lieberman, D. E. (2012). Foot strike and injury rates in endurance runners: A retrospective study. Medicine \& Science in Sports \&Exercise, 44(7), 1325-1334. https://doi. org/10.1249/MSS.0b013e3182465115

Davis, I. S. (2014). The re-emergence of the minimal running shoe. Journal of Orthopaedic and Sports Physical Therapy, 44(10), 775-784. https://doi. org/10.2519/jospt.2014.5521

De Wit, B., De Clercq, D., \& Aerts, P. (2000). Biomechanical analysis of the stance phase during barefoot and shod running. Journal of Biomechanics, 33(3), 269-278. https://doi.org/10.1016/50021-9290(99)00192-X

Derrick, T. R., Hamill, J., \& Caldwell, G. E. (1998). Energy absorption of impacts during running at various stride lengths. Medicine \& Science in Sports \& Exercise, 30(1), 128-135. https://doi.org/10.1097/00005768-199801000-00018

Emborg, J., Spaich, E. G., \& Andersen, O. K. (2009). Withdrawal reflexes examined during human gait by ground reaction forces: Site and gait phase dependency. Medical and Biological Engineering and Computing, 47(1), 29-39. https://doi. org/10.1007/s11517-008-0396-x

Enoka, R. M. (2008). Neuromechanics of human movement (4th ed.). Human Kinetics.

Fellin, R. E., Manal, K., \& Davis, I. S. (2010). Comparison of lower extremity kinematic curves during overground and treadmill running. Journal of Applied Biomechanics, 26(4), 407-414. https://doi.org/10.1123/jab.26.4.407

Fuller, J. T., Bellenger, C. R., Thewlis, D., Tsiros, M. D., \& Buckley, J. D. (2015). The effect of footwear on running performance and running economy in distance runners. Sports Medicine, 45(3), 411-422. https://doi.org/10.1007/ s40279-014-0283-6

Gruber, A. H., Umberger, B. R., Jewell, C., del Pilar, S., II, \& Hamill, J. (2011). Achilles tendon forces in forefoot and rearfoot running. In Proceedings of the 35th Annual Meeting of the American Society of Biomechanics. https://www.asbweb. org/wp-content/uploads/2011ASBmeetingproceedings.pdf

Hall, J. P. L., Barton, C., Jones, P. R., \& Morrissey, D. (2013). The biomechanical differences between barefoot and shod distance running: A systematic review and preliminary meta-analysis. Sports Medicine, 43(12), 1335-1353. https://doi. org/10.1007/s40279-013-0084-3

Jandová, S., Charousek, J., \& Janura, M. (2019). Comparison of foot loading and foot strike pattern in women running in minimalist and conventional sports shoes. Acta Gymnica, 49(1), 40-46. https://doi.org/10.5507/ag.2019.003

Koop, J., \& Rutberg, J. (2016). Training essentials for ultrarunning. VeloPress.

Lieberman, D. E., Venkadesan, M., Werbel, W. A., Daoud, A. I., D’Andrea, S., Davis, I. S., Mang'En, R. O., \& Pitsiladis, Y. (2010). Foot strike patterns and collision forces in habitually barefoot versus shod runners. Nature, 463(7280), 531-535. https://doi.org/10.1038/nature08723

McCallion, C., Donne, B., Fleming, N., \& Blanksby, B. (2014). Acute differences in foot strike and spatiotemporal variables for shod, barefoot or minimalist male runners. Journal of Sports Science and Medicine, 13(2), 280-286.

McDougall, C. (2009). Born to run: A hidden tribe, superathletes, and the greatest race the world has never seen. Alfred A. Knopf

McGinnis, P. M. (2013). Biomechanics of sport and exercise. Human Kinetics.

Müller, R., Grimmer, S., \& Blickhan, R. (2010). Running on uneven ground: Leg adjustments by muscle pre-activation control. Human Movement Science, 29(2), 299-310. https://doi.org/10.1016/i.humov.2010.01.003

Nigg, B. M., De Boer, R. W., \& Fisher, V. (1995). A kinematic comparison of overground and treadmill running. Medicine \& Science in Sports \& Exercise, 27(1), 98-105.

Outdoor Foundation \& Montrail. (2010). A special report on trail running. https:// outdoorindustry.org/wp-content/uploads/2017/06/2010-A-Special-Report-on-Trail-Running1.pdf

Rice, H. M., Jamison, S. T., \& Davis, I. S. (2016). Footwear matters: Influence of footwear and foot strike on load rates during running. Medicine \& Science in Sports \& Exercise, 48(12), 2462-2468. https://doi.org/10.1249/MSS.0000000000001030

Robbins, S. E., \& Gouw, G. J. (1990). Athletic footwear and chronic overloading. Sports Medicine, 9(2), 76-85. https://doi.org/10.2165/00007256-199009020-00002

Sinclair, J., Butters, B., \& Stainton, P. (2018). Acute effects of barefoot and minimalist footwear on medial tibiofemoral compartment loading during running. A statistical parametric mapping approach. Journal of Human Kinetics, 65(1), 35-44. https://doi.org/10.2478/hukin-2018-0037

Spaich, E. G., Emborg, J., Collet, T., Arendt-Nielsen, L., \& Andersen, O. K. (2009). Withdrawal reflex responses evoked by repetitive painful stimulation delivered on the sole of the foot during late stance: Site, phase, and frequency modulation. Experimental Brain Research, 194(3), 359-368. https://doi.org/10.1007/ s00221-009-1705-9 
Squadrone, R., \& Gallozzi, C. (2009). Biomechanical and physiological comparison of barefoot and two shod conditions in experienced barefoot runners. Journal of Sports Medicine and Physical Fitness, 49(1), 6-13.

Squadrone, R., Rodano, R., Hamill, J., \& Preatoni, E. (2015). Acute effect of different minimalist shoes on foot strike pattern and kinematics in rearfoot strikers during running. Journal of Sports Sciences, 33(11), 1196-1204. https://doi.org/1 $0.1080 / 02640414.2014 .989534$

Sterzing, T., Apps, C., Ding, R., \& Cheung, J. T.-M. (2014). Running on an unpredictable irregular surface changes lower limb biomechanics and subjective perception compared to running on a regular surface. Journal of Foot and Ankle Research, 7(Suppl. 1), Article A80. https://doi.org/10.1186/1757-1146-7-s1-a80

Tam, N., Darragh, I. A. J., Divekar, N. V., \& Lamberts, R. P. (2017). Habitual minimalist shod running biomechanics and the acute response to running barefoot. International Journal of Sports Medicine, 38(10), 770-775. https://doi. org/10.1055/s-0043-114863

Thompson, M. A., Lee, S. S., Seegmiller, J. \& McGowan, C. P. (2015). Kinematic and kinetic comparison of barefoot and shod running in $\mathrm{mid} /$ forefoot and rearfoot strike runners. Gait \& Posture, 41(4), 957-959. https://doi.org/10.1016/i. gaitpost.2015.03.002

Vercruyssen, F., Tartaruga, M., Horvais, N., \& Brisswalter, J. (2016). Effects of footwear and fatigue on running economy and biomechanics in trail runners. Medicine \& Science in Sports \& Exercise, 48(10), 1976-1984. https://doi. org/10.1249/MSS.0000000000000981

Voloshina, A. S., \& Ferris, D. P. (2015). Biomechanics and energetics of running on uneven terrain. Journal of Experimental Biology, 218(5), 711-719. https:// doi.org/10.1242/ieb.106518 